\title{
Relation between the Area Affected by Fournier's Gangrene and the Type of Reconstructive Surgery Used. A Study with 80 Patients
}

\author{
Joao P. Carvalho, Andre Hazan, Andre G. Cavalcanti, Luciano A. Favorito \\ Division of Urology, Souza Aguiar Municipal Hospital, Rio de Janeiro, RJ, Brazil
}

\begin{abstract}
Objective: To assess the affected skin area and the reconstructive techniques used in 80 patients affected by Fournier's gangrene.

Materials and Methods: Eighty patients ranging in age from 19 to 85 years (mean = 51) affected by Fournier's gangrene were studied. When admitted to the emergency room the patients were submitted to clinical and laboratory examinations to analyze the gravity of the case. All patients were submitted to an extensive debridement of the lesion, urinary derivation by cystostomy and colostomy whenever necessary.

Results: Only 13 patients (16.25\%) died. From the 67 remaining patients, in $44(65.6 \%)$ debridement was restricted to the scrotum, in $10(14.9 \%)$ there has been scrotum and penile lesions and in $13(19.3 \%)$ there has been a debridement of the scrotum and the perineal region. In 11 cases $(16.4 \%)$ there was no need for reconstructive surgery with wound closing by second intention, in 16 cases $(23.8 \%)$ reconstructive surgery was performed with mobilization of local skin, in $19(28.3 \%)$ we have used skin grafts, 20 patients $(29.8 \%)$ needed reconstructive surgery with the use of skin flaps and in 1 case $(1.4 \%)$ there has been the use of skin flaps and grafts simultaneously.

Conclusions: Fournier's gangrene is a serious pathology and should be treated aggressively with an extensive debridement of the area with necrosis. The use of precocious reconstructive surgery of the genitals present good results and tends to greatly reduce the length of hospital stay and improve the psychological conditions of these patients.
\end{abstract}

Key words: scrotum; genitalia; infection; Fournier's gangrene; reconstructive surgical procedures

Int Braz J Urol. 2007; 33: 510-4

\section{INTRODUCTION}

The occurrence of gangrene in the genitals is rare but potentially lethal (1). The Fournier's gangrene is characterized by an acute necrotizing fasciitis of an infectious origin that affects the genital, perineal and perianal regions. The infectious process leads to a thrombosis of the subcutaneous vessels resulting in skin gangrene (2). The Fournier's gangrene is an urologic urgency that needs a precocious diagnosis and aggressive treatment with the use of wide spectrum antibiotics and surgical debridement $(1,3)$.

In spite of the development of new treatment techniques, the rate of mortality of Fournier's gangrene is close to $50 \%(2,4)$. Many conditions are associated to this pathology, the main ones are diabetes, alcoholism, immunosupression, local trauma and genitourinary infections (2). Patients presenting with acquired immunodeficiency syndrome also present a higher predisposition to the disease (2). The clinical 
condition presents evolution from 2 to 7 days and is characterized by uneasiness, fever, gangrene of the genitals and leukocytosis (5). Generally, the infection is caused by 3 or more germs, being the most common the E. coli, Proteus, Enterococcus and anaerobes $(2,6)$.

The treatment of choice for the Fournier's gangrene is aggressive surgical debridement. The use of hyperbaric therapy with oxygen is an adjuvant treatment to this pathology, recently described and with satisfactory results (7). The surgical wound can heal by second intention or need further flaps or grafts for a better evolution (8).

The aim of this work is to correlate the extension of the genital area affected by the Fournier's gangrene with the type of treatment used to reconstruct the genitals.

\section{MATERIALS AND METHODS}

From January 1996 to January 2006, 80 patients ranging in age from 19 to 85 years $($ mean $=$ 51.18) affected with Fournier's gangrene were studied. When admitted in the emergency room the patients were submitted to clinical and laboratory exams to analyze the gravity of the case. The typical aspect of the genitals of a patient with Fournier's gangrene is demonstrated in Figure-1. After assessment

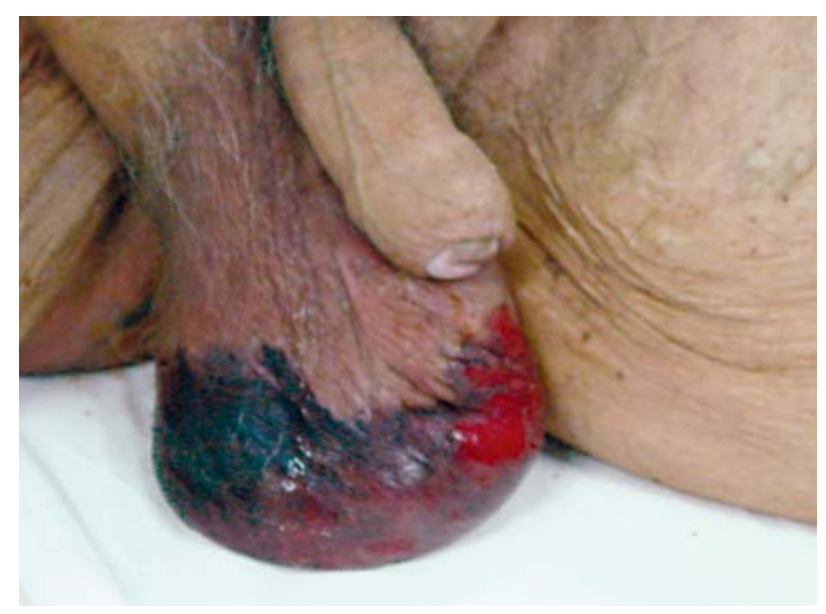

Figure 1 - Patient presenting Fournier's gangrene affecting the scrotum. of pulse, respiratory frequency, arterial blood pressure and temperature and the presence of associated pathologies, they were submitted to blood analyses, including electrolytes, creatinine, leukocytes, hematocrit, glucose and serum bicarbonate.

All patients had the gangrene area quantified according to the classification mentioned by Laor et al. (9) and divided in the following groups: A) Isolated gangrene of the scrotum, B) gangrene of the penis and scrotum, C) gangrene of the scrotum with extension into the perineum and D) Gangrene with extension up to the abdominal wall. After classification, the patients were submitted to an extensive debridement of the lesion, urinary derivation with cystostomy and colostomy whenever necessary.

\section{RESULTS}

Only 13 patients (16.25\%) died due to septic shock, from those three died during debridement and 10 in the immediate postoperative period. Laboratorial exams of the dead patients presented important alterations in the full blood count, glucose and renal function. Because they were submitted to a reconstructive treatment of the genitalia, these patients were excluded from the study. The division of the 67 remaining patients according to the area of necrosis can be seen in Table-1. From the 67 patients, 44 (65.6\%) were from group A, with a lesion restricted to the scrotum, 10 (14.9\%) were from group B, presenting a lesion of the scrotum and penis (Figure-2),

Table 1 - Distribution of the 67 patients divided in 4 groups according to the area affected by Fournier's gangrene. A) Isolated gangrene of the scrotum, B) Gangrene of the penis and scrotum, C) Gangrene of the scrotum with extension into the perineum, D) Gangrene with extension up to abdominal wall.

\begin{tabular}{ll}
\hline Groups & Cases $(\%)$ \\
\hline A & $44(65.6 \%)$ \\
B & $10(14.9 \%)$ \\
C & $12(17.9 \%)$ \\
D & $01(1.4 \%)$ \\
Total & $67(100 \%)$ \\
\hline
\end{tabular}




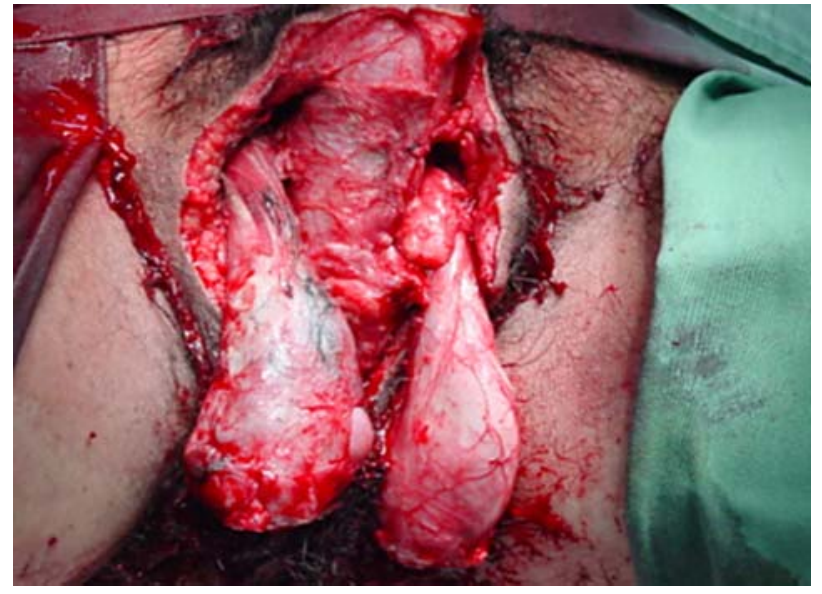

Figure 2 - Patient presenting Fournier's gangrene after debridement. The lesion affected the scrotum and the penis. Note bilateral exposure of the testes.

$12(17.9 \%)$ were from group $\mathrm{C}$, being necessary the debridement of the scrotum and perineal region and 1 patient (1.4\%) was from group D, presenting necrosis extending into the abdominal wall.

In 27 cases (30.2\%), all from group A, there was no need for plastic surgery with rotation flaps or grafts; in 11 cases the wound closure was by second intention and in 16 cases reconstructive surgery was performed with local skin mobilization. In 19 cases (28.3\%); 9 from the group A and 10 from the group $\mathrm{B}$, we have used skin graft (Figure-3); 20 patients (29.8\%) need a reconstructive surgery with the use

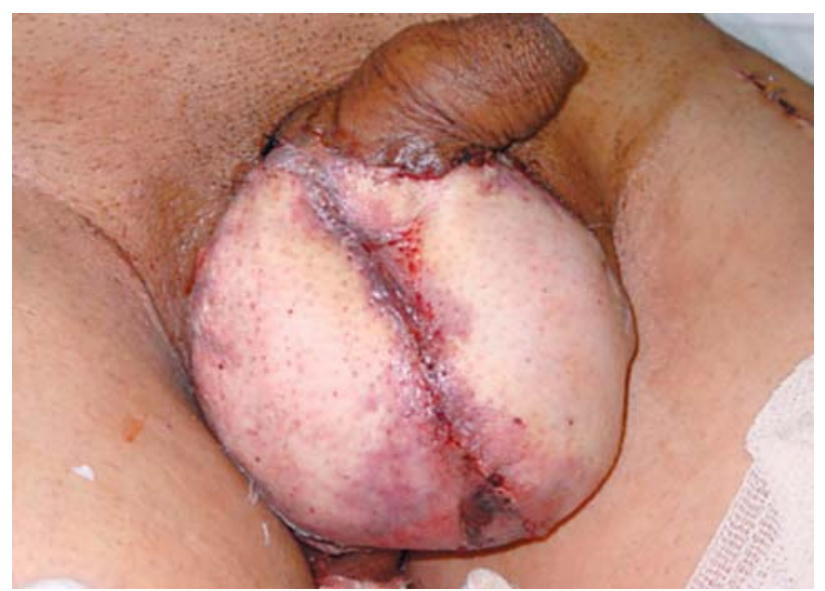

Figure 3 - Postoperative aspect of the reconstructive surgery of the scrotum with thigh skin graft. of skin flap ( 8 from group A and 12 from group C) and in 1 case (1.4\%) there has been a use of flap and graft simultaneously, in a patient from Group D (Table-2).

Complications of reconstructive surgery occurred in 7 cases (9.8\%), being infection in 5 cases ( 3 patients submitted to grafts and 2 submitted to flap) and loss of flap in 2 cases.

\section{COMMENTS}

Aggressive treatment with extensive debridement of the lesion and the use of broad-spectrum antibiotics is the best chance of cure for Fournier's gangrene $(6,10)$. Previous studies demonstrated that $100 \%$ of the patients that were not submitted to debridement died (11), while only $6 \%$ of the patients submitted to debridement died. Some authors commend debridement for both the tissue with apparent necrosis and the tissue with doubtful viability and extension to health areas (5); however, this more aggressive treatment can be challenged because it leads to larger tissue loss making it more difficult the healing and extending the patient's recovery period (5).

One of the most important prognostic factors in gangrene of the genitals is the extension of the necrosis (9). Patients with gangrene area between 0 and $3 \%$ rarely die (12), while patients that present with an area affected by the gangrene larger that $5 \%$ have a poor prognostic (12).

The scrotum was the area most commonly affected by the gangrene. In our study in most of the cases, it was restricted to the scrotum (65.6\%) and in $14.9 \%$, it was associated to penile lesions. In a previous study by Benizri et al. (5), there is evidence that

Table 2 - Type of treatment used in the 67 patients affected with Fournier's gangrene.

\begin{tabular}{ll}
\hline Type of Reconstruction & Cases (\%) \\
\hline Closure by second intention & $11(16.4 \%)$ \\
Local skin mobilization & $16(23.8 \%)$ \\
Skin graft & $19(28.3 \%)$ \\
Skin flap & $20(29.8 \%)$ \\
Flap + graft & $01(1.4 \%)$ \\
Total & $67(100 \%)$ \\
\hline
\end{tabular}


in most of the cases the Fournier's gangrene affects the scrotum or the penis isolatedly (5). In this study, there were a significant number of cases presenting extension to the abdominal wall (54\%) (5), which were rare in our series, occurring in only 3 of 80 patients studied $(3.75 \%)$.

Surgical debridement can lead to extensive skin defects of the genitalia, perineum and anterior abdominal wall. Even though these defects present a satisfactory healing by second intention, this process can be slow and reconstructive surgery might be necessary (13).

Reconstructive surgery of the genitalia in Fournier's gangrene can be considered only after an improvement of the patient's clinical condition (13). The main objective of the genitalia reconstruction in Fournier's gangrene is efficient coverage of skin loss with maintenance of penile functions (erection, ejaculation and voiding) (13-15).

The extension of the disease and the mortality rate are controversial themes in literature. Some studies report that the extension of the disease is related to a higher death rate (16), while other studies report that the extension of the gangrene do not relate to a poorer prognosis (4). The extension of the gangrene should be analyzed together with the clinical condition of the patient and the Fournier's gangrene severity index, recently described, is a good prognostic value to the patient's evolution (17). In our study from the 13 patients that died 6 were from group A, 5 from group B and only 2 presented with the gangrene affecting the abdominal wall (group D).

The skin defects of the external genitalia and of the perineum lead to a significant morbidity and the reconstructive surgery with coverage of the lesion leads to a fast and good improvement of the patient (8). Many authors use the remaining prepuce or the scrotal skin to cover skin defects (13), however free grafts are easy to be done, are versatile and present good cosmetic aspects. The flaps present superior cosmetic aspects, even though the donating sites are limited and present a higher morbidity (8). The grafts are frequently used in the treatment of traumas, burns, avulsions and suppurative hidradenitis, presenting better results in contaminated areas.

From the 40 patients that needed reconstructive surgery in only 7 (9.8\%) we observe complica- tions, without statistical significant difference between the graft and the flap. In the other 33 patients $(90.2 \%)$, the reconstructive surgery did not present complications and the esthetic aspect was satisfactory.

\section{CONCLUSION}

The Fournier's gangrene is a serious pathology with a high mortality rate and should be treated aggressively with antibiotic therapy and extensive debridement of the area presenting necrosis. The use of precocious reconstructive surgery of the genitalia present satisfactory results and tends to reduce the period of hospital stay and improve the psychological conditions of these patients.

\section{REFERENCES}

1. Smith GL, Bunker CB, Dinneen MD: Fournier's gangrene. Br J Urol. 1998; 81: 347-55.

2. Paty R, Smith AD: Gangrene and Fournier's gangrene. Urol Clin North Am. 1992; 19: 149-62.

3. Eke N: Fournier's gangrene: a review of 1726 cases. Br J Surg. 2000; 87: 718-28.

4. Clayton MD, Fowler JE Jr, Sharifi R, Pearl RK: Causes, presentation and survival of fifty-seven patients with necrotizing fasciitis of the male genitalia. Surg Gynecol Obstet. 1990; 170: 49-55.

5. Benizri E, Fabiani P, Migliori G, Chevallier D, Peyrottes A, Raucoules M, et al.: Gangrene of the perineum. Urology. 1996; 47: 935-9.

6. Baskin LS, Carroll PR, Cattolica EV, McAninch JW: Necrotising soft tissue infections of the perineum and genitalia. Bacteriology, treatment and risk assessment. Br J Urol. 1990; 65: 524-9.

7. Mindrup SR, Kealey GP, Fallon B: Hyperbaric oxygen for the treatment of fournier's gangrene. J Urol. 2005; 173: 1975-7.

8. Black PC, Friedrich JB, Engrav LH, Wessells H: Meshed unexpanded split-thickness skin grafting for reconstruction of penile skin loss. J Urol. 2004; 172: 976-9.

9. Laor E, Palmer LS, Tolia BM, Reid RE, Winter HI: Outcome prediction in patients with Fournier's gangrene. J Urol. 1995; 154: 89-92.

10. Hejase MJ, Simonin JE, Bihrle R, Coogan CL: Genital Fournier's gangrene: experience with 38 patients. Urology. 1996; 47: 734-9. 
11. Sanchez Mazzaferri F, Fadil Iturralde JL, Provenzal O, Damiani H, Milman A, Bragagnolo J, et al.: Fournier's gangrene. Our experience over 10 years. A review of the literature. Arch Esp Urol. 1999; 52: 721-7.

12. Dahm P, Roland FH, Vaslef SN, Moon RE, Price DT, Georgiade GS, et al.: Outcome analysis in patients with primary necrotizing fasciitis of the male genitalia. Urology. 2000; 56: 31-6.

13. Parkash S, Gajendran V: Surgical reconstruction of the sequelae of penile and scrotal gangrene: a plea for simplicity. Br J Plast Surg. 1984; 37: 354-7.
14. Brissiaud JC, Azam P, Paret B, Lopy J, Louis C, Collet F: Skin gangrene of the external genitalia. Report of 44 cases. Chirurgie. 1998; 123: 387-93.

15. Vincent MP, Horton CE, Devine CJ Jr: An evaluation of skin grafts for reconstruction of the penis and scrotum. Clin Plast Surg. 1988; 15: 411-24.

16. Spirnak JP, Resnick MI, Hampel N, Persky L: Fournier's gangrene: report of 20 patients. J Urol. 1984; 131: 289-91.

17. Yeniyol CO, Suelozgen T, Arslan M, Ayder AR: Fournier's gangrene: experience with 25 patients and use of Fournier's gangrene severity index score. Urology. 2004; 64: 218-22.

\author{
Correspondence address: \\ Dr. Luciano Alves Favorito \\ Rua Professor Gabizo 104/201 \\ Rio de Janeiro, RJ, 20271-320, Brazil \\ Fax: + $55213872-8802$ \\ E-mail: lufavorito@yahoo.com.br
}

